\title{
BMJ Open Knowledge, perceptions and practices of pharmacists regarding generic substitution in China: a cross- sectional study
}

\author{
Jinghan Qu, ${ }^{1}$ Wei Zuo, ${ }^{1}$ Shaohong Wang, ${ }^{1}$ Liping Du, ${ }^{1}$ Xin Liu, ${ }^{1}$ Yang Gao, \\ Jiantao Li, ${ }^{1}$ Hui Pan (D) , ${ }^{2}$ Xiaoli Du, ${ }^{1}$ Dan Mei, ${ }^{1}$ Roxane L Took, ${ }^{3}$ \\ Kenneth W Schafermeyer, ${ }^{4}$ Stephanie Lukas, ${ }^{4}$ Bo Zhang (iD ${ }^{1}$
}

To cite: Qu J, Zuo W, Wang S, et al. Knowledge, perceptions and practices of pharmacists regarding generic substitution in China: a crosssectional study. BMJ Open 2021;11:e051277. doi:10.1136/ bmjopen-2021-051277

- Prepublication history and additional supplemental material for this paper are available online. To view these files, please visit the journal online (http://dx.doi.org/10.1136/ bmjopen-2021-051277).

JQ and WZ contributed equally.

Received 17 March 2021 Accepted 27 September 2021

Check for updates

(c) Author(s) (or their employer(s)) 2021. Re-use permitted under CC BY-NC. No commercial re-use. See rights and permissions. Published by BMJ.

For numbered affiliations see end of article.

Correspondence to

Professor Bo Zhang;

zhangbopumch@163.com

\section{ABSTRACT}

Objective To evaluate pharmacists' knowledge, perceptions and practices towards generic substitution in the 11 pilot locations in China.

Design An online cross-sectional survey using questionnaires was conducted. A convenience sampling technique was implemented to recruit pharmacists.

Setting and participants The study took place in medical institutions of 11 pilot locations that participated in the pilot national centralised procurement programme in 2019. Two thousand two hundred and ninety-one pharmacists including hospital pharmacists or community pharmacists based on health-systems or clinics participated in the study.

Results Most of the participants had the good knowledge of requirements for evaluating the quality and efficacy of generic drugs $(n=2118 ; 92.4 \%)$, and the definition of generic drugs $(n=2078 ; 90.7 \%)$. In terms of perceptions, $67.3 \%$ of respondents were of the opinion that generic drugs are equally as effective as the brand-name drugs, and $69.0 \%$ of respondents were of the opinion that generic drugs are as safe as brand equivalents. A high percentage of participants supported the policy of generic substitution $(\mathrm{n}=1634 ; 71.4 \%)$. A significant positive correlation was demonstrated between total knowledge score and total perception score $(\rho=0.267 ; p<0.001)$. Efficacy, safety and the direction of national policies and hospital regulations were the main factors affecting pharmacists' willingness to dispense generic drugs.

Conclusions The study identified gaps in respondents' knowledge and perceptions of generic substitution. Pharmacists who are more knowledgeable in generic drugs tend to hold a more supportive attitude towards generic substitution. Although it appeared that pharmacists in China have largely accepted generic substitution, they still have concerns regarding the reliability and quality of generic drugs. The current issues need to be addressed for the realisation of the true value of generic drugs as part of the country's healthcare cost-containment strategy as well as the implementation of generic substitution policy in China.

\section{INTRODUCTION}

Healthcare expenditures have been constantly increasing worldwide, ${ }^{12}$ and expenditure on

\section{STRENGTHS AND LIMITATIONS OF THIS STUDY}

$\Rightarrow$ This cross-sectional study is one of the few surveys evaluating the knowledge, perceptions and practices of pharmacists regarding generic drugs after implementing the national centralised procurement in China.

$\Rightarrow$ The current findings have important implications in improvement of generic drugs policy and its implementation.

$\Rightarrow$ This survey recruited a large number of respondents $(n=2291)$. The Cronbach's alpha value for perceptions is equal to 0.833 , indicating a good level of reliability.

$\Rightarrow$ The web-based sample survey tool could be a limitation because of non-randomised sampling.

$\Rightarrow$ This study was performed in only 11 locations in China, which could limit generalisability of the findings.

drugs is one of the fastest growing components of healthcare spending. ${ }^{3-5}$ Generic drugs offer an opportunity for substantial savings to healthcare systems. Currently, generic drug prescribing has become a major cost-minimising strategy to reduce the fiscal expenditures and financial burden to patients, and to increase accessibility to essential drugs globally. The WHO defined a generic drug as 'a pharmaceutical product, usually intended to be interchangeable with an innovator product that is manufactured without a license from the innovator company and marketed after the expiry date of the patent or other exclusive rights'. ${ }^{6}$ Generic substitution is defined as the act of substituting a brand-name drug with an equivalent generic drug. ${ }^{7}$

In China, overall medical expenditures accounted for $6.57 \%$ of the gross domestic product (GDP) in 2018. ${ }^{8}$ Approximately $28 \%$ of medical expenditures came from the 
government. ${ }^{8}$ Overall medical expenditures in China steadily increased between 2008 and 2017, at an average annual rate of $12.2 \%$, outpacing the real GDP growth of $8.1 \% .^{9}$ The per-capita drug consumption in China has risen to the highest in the world. ${ }^{10}$

Controlling drug expenses in public hospitals is vital in controlling overall medical expenditures. According to Alexandra's statistics, ${ }^{11}$ due to the large volumes of medications consumed in public hospitals and a substantial price differential between the originator brand and lowest-priced generic products, US $\$ 370$ million could be saved by switching only four drugs, saving patients an average of $65 \%$. With the March 2019 implementation of the national centralised procurement programme, generic substitution in China has become an irresistible trend. $^{12}{ }^{13}$ This programme directed by the authorities was a new procurement model for drugs based on volume and bidding, with public institutions forming a procurement alliance.

China has become the second largest producer of pharmaceuticals in the world and is still growing rapidly. ${ }^{14} 15$ There are more than 8135 pharmaceutical companies in China, most of which produce generic drugs. Ensuring that the large amounts of pharmaceutical products in the market are therapeutically equivalent has been challenging for Chinese authorities. Thus in 2013, the National Medical Products Administration (NMPA), formally known as the China Food and Drug Administration, established a system to evaluate generic quality. ${ }^{16}$ According to the regulations issued by the government in March 2016, ${ }^{17}$ assessment of quality and efficacy via 'consistency evaluation' is mandatory for generic drugs approved prior to 2007 in the National Essential Medicine List (2012). The NMPA requires that the 90\% CI of the geometric mean ratio for main pharmacokinetic parameters, the peak concentration and the area under concentration-time curve, of the product fall entirely within the range of $80.00 \%-125.00 \%$ in order to be bioequivalent. ${ }^{18}$ By 27 November 2019, 323 drug products passed the consistency evaluation for quality and efficacy. ${ }^{19}$ In the released NMPA standard reference product list, referenced products were selected from the brand equivalent or the same species acknowledged worldwide if the brand equivalent was not available.

The national centralised procurement programme was approved by the State Council in January 2019 to significantly lower drug prices and to improve accessibility of drugs. Four municipalities and seven local cities were selected as the pilot cities, including Beijing, Tianjin, Shanghai, Chongqing, Shenyang, Dalian, Xiamen, Guangzhou, Shenzhen, Chengdu, Xi-an. Twenty-five drug products were selected in the pilot programme, of which 22 were generic drugs that had previously passed the consistency evaluation and three were brand-name drugs. Drug manufacturers bid to be contracted in this pilot programme, and the successful manufacturers established a contract with an agreed on purchase amount. By setting up this contract, the drug purchase price dropped dramatically. Generic drugs accounted for $63 \%$ of the Chinese market in $2018 .{ }^{20}$ Due to the drug price gap between brand drugs and generic drugs, the brand drugs are highly accessible in large cities, while generic drugs are more accessible in small cities or rural areas. After the implementation of the national centralised procurement policy, the price of selected generic varieties decreased, subsequently the brand drugs price significantly declined, which promote access to the brand and generic drugs. The selected generic varieties almost accounted for all market shares among non-brand drugs in the pilot locations. ${ }^{21}$ By the end of 2019, the pilot programme was extended to more cities and provinces forming a procurement alliance, which covered nearly all the Chinese mainland. The generic substitution policy evolved from this pilot; because more generic drugs cheaper than the originator brand went into the procurement programme under the bidding mechanism and made up a large market share.

As essential members of healthcare system, pharmacists play an important role in spreading awareness about the generic substitution policy. Pharmacists advise physicians on the selection, dosages, interactions and side effects of generic drugs in collaboration practice, and provide education and counselling about generic drugs for patients when dispensing drugs according to medical prescription. The primary objective of this study was to investigate the knowledge, perceptions and practices of Chinese pharmacists regarding generic substitution after completion of the pilot year.

\section{METHODS}

\section{Study design}

A self-administered, anonymous, online cross-sectional survey was conducted among hospital pharmacists or community pharmacists based on health-systems or clinics in the 11 pilot locations in China between April and May 2020. The 11 pilot locations were those participated in the national centralised procurement programme in 2019.

\section{Questionnaire design}

The questionnaire was developed in the Chinese language after extensive literature search and review. ${ }^{22-28}$ The first draft of the questionnaire consisted of 32 items. The preliminary version of the questionnaire was peerreviewed by 7 researchers, and assessed by 10 experts for appropriateness of clinical terminology, completeness, accuracy and logical sequence of the statements. Based on the suggestions, we refined it and deleted four items-the type of medical institutions, the familiarity with generic drugs, the knowledge of policy on generic drugs and perceptions on access to generic drugs. Then the questionnaire was piloted among a sample of 20 hospital pharmacists in Beijing to test the reliability and validity of the questionnaire. The data of the pilot study (online supplemental table S1 and S2) were not included in the final study's statistical analysis. Minor changes were made according to feedbacks on ambiguities. The 
final questionnaire consisted of 29 items (online supplemental file 2). Survey questions were created on the Wenjuanxing website and were divided into four sections (demographic information, knowledge about generic drugs, perceptions towards generic substitution and practices on generic substitution).

\section{Section I: demographic information}

The first section assessed pharmacists' demographic data including respondents' age, gender, terminal degree, professional title, years in practice, secondary department (eg, outpatient, inpatient, clinical, laboratory, etc) and geographical location.

\section{Section II: knowledge about generic drugs}

The second section contained five questions evaluating pharmacists' knowledge of the consistency evaluation for generic drugs and national policies related to the national centralised procurement programme. For knowledgebased questions, respondents self-assessed their level of knowledge on these three questions by indicating either 'yes', 'no' or 'unsure'. Response of 'yes' were given 1 point, and responses of 'no' or 'unsure' were scored zero. For true or false questions, correct responses were given 1 point, and a wrong or unsure response was scored zero. The maximum score on this knowledge section was 5 points.

\section{Section III: perceptions towards generic substitution}

The third section explored pharmacists' perception of generic substitution with 10 items; a 5-point Likert scale was used to measure the level of respondents' agreement with offered statements. Response of strong disagreement was given 1 point and strong agreement was given 5 point. For statistical reasons, the fifth question was reverse scored from 1 (strong agreement) to 5 point (strong disagreement). The maximum score on this perception section was 50 points.

\section{Section IV: practices on generic substitution}

In the fourth section, the practices, influencing factors, and difficulties related to generic substitution were examined. This section contained five multiple choice questions. For the last four questions, respondents were asked to select the top three important items.

\section{Data collection}

On 14 April 2020, the Wenjuanxing hyperlink for this survey was shared with pharmacist groups in the 11 pilot locations in China using WeChat, a multipurpose messaging app. Informed consent from all respondents was gained prior to the commencement of the questionnaire. In order to submit the questionnaire, respondents had to complete all fields. Respondents were given approximately 3 weeks to complete the survey. The online survey was closed on 6 May 2020. Data from the survey were synchronously collected using Wenjuanxing website as soon as each respondent had finished the questionnaire.

\section{Inclusion and exclusion criteria}

Pharmacists including hospital pharmacists or community pharmacists based on health-systems or clinics in the 11 locations were included in the survey. Data from other professionals in the medical institutions were excluded. Participation was voluntary; no incentive was provided for enrollment of participants.

\section{Patient and public involvement}

Patients and/or public were not involved in this research.

\section{Statistical analysis}

Data were analysed with SPSS V.24. Reliability analysis (Cronbach alpha coefficient) of items focused on the perceptions towards generic substitution was applied. Normality of the data was tested using KolmogorovSmirnov test. If the data did not comply with the normal distribution, Mann-Whitney U or Kruskal-Wallis tests were used to compare differences and Spearman's rank correlation was applied to determine associations among variables. $\mathrm{P}$ values $<0.05$ were considered significant.

\section{RESULTS}

\section{Demographics of respondents}

A total of 2291 pharmacists participated in the study. Nearly half of respondents $(1130 ; 49.3 \%)$ were in the age group of 30-39 years, and about a quarter of respondents (530; $23.1 \%$ ) were in the group of 40-49 years. The majority of respondents $1658(72.4 \%)$ were female. The majority of pharmacists worked in a tertiary hospital setting (1913; $83.5 \%)$ and had a bachelor's degree (1487; 64.9\%). Four hundred and forty-two (19.3\%) of the respondents were senior pharmacists, 928 (40.5\%) of the respondents were pharmacists-in-charge and $867(37.8 \%)$ were primary pharmacists. More details regarding the demographic and professional characteristics are presented in table 1.

\section{Knowledge about generic drugs}

Knowledge of generic drugs was tested in five questions (for a total of 5 points), and the median knowledge score was 4.00 (mean \pm SD: $3.58 \pm 0.956$ ). However, table 1 shows statistically significant differences in knowledge scores related to variances in demographic and professional characteristics. Pharmacists within the range of 40-49 years had the highest score of knowledge (mean $\pm \mathrm{SD}$ : $3.71 \pm 0.989$ ), followed by those of $50-59$ years (mean \pm SD: $3.68 \pm 0.819$ ) and more than 60 years (mean \pm SD: $3.60 \pm 0.966)$. Men scored significantly higher than women (mean: 3.66 vs $3.55 ; \mathrm{p}<0.05$ ). Among different levels of terminal degrees and professional titles, pharmacists with doctoral degrees $($ mean \pm SD: $3.75 \pm 0.783)$ or higher professional titles $($ mean \pm SD: $3.90 \pm 0.799)$ were more knowledgeable of generic drugs.

Table 2 represents pharmacists' responses to the knowledge items. The vast majority of the respondents understood that the government has carried out the programme of consistency evaluation (2118; 92.4\%), and that generic 


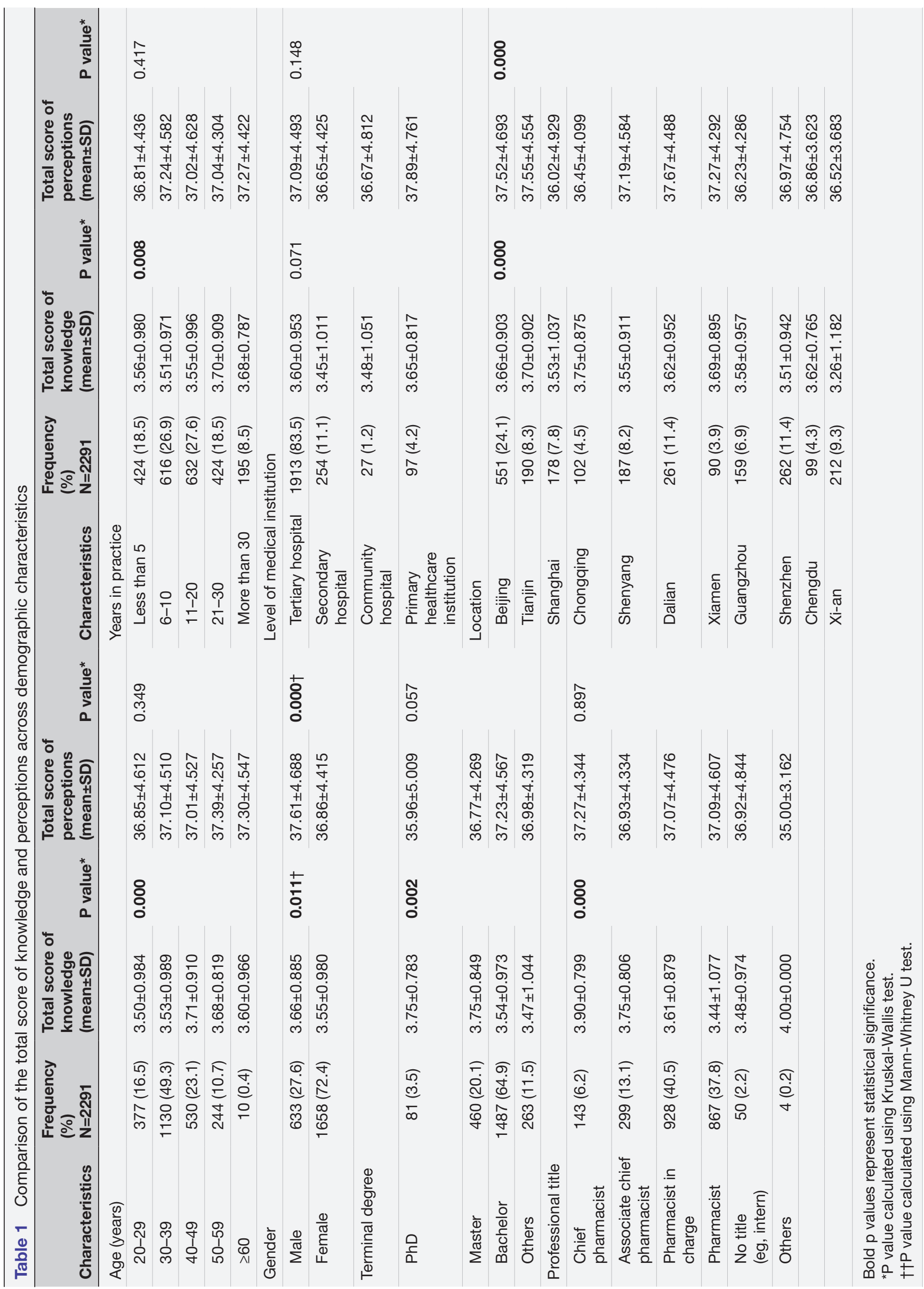


Table 2 Pharmacists' knowledge about generic drugs

\begin{tabular}{|c|c|c|c|}
\hline Statement & $\begin{array}{l}\text { Yes or correct } \\
\text { response, } \mathrm{N}(\%)\end{array}$ & $\begin{array}{l}\text { No or incorrect } \\
\text { response, } \mathrm{N}(\%)\end{array}$ & $\begin{array}{l}\text { Unsure } \\
\text { N (\%) }\end{array}$ \\
\hline $\begin{array}{l}\text { Were you aware that China carries out the programme of quality and } \\
\text { efficacy consistency evaluation of generic drugs? }\end{array}$ & $2118(92.4)$ & $74(3.2)$ & $99(4.3)$ \\
\hline $\begin{array}{l}\text { Were you aware of the logo 'Have passed the Consistency } \\
\text { Evaluation' on the generic products? }\end{array}$ & 1718 (75.0) & $320(14.0)$ & 253 (11.0) \\
\hline $\begin{array}{l}\text { True/false: in principle, the method of bioequivalence tests in vivo is } \\
\text { used for consistency evaluation. The standard of bioequivalence is } \\
\text { that the } 90 \% \mathrm{Cl} \text { of the geometric mean experiment/ reference ratios } \\
\text { for main pharmacokinetic parameters (Cmax and AUC) falls entirely } \\
\text { within the range of } 90.00 \% \sim 120.00 \% \text {. }\end{array}$ & 225 (9.8) & 1666 (72.7) & 400 (17.5) \\
\hline $\begin{array}{l}\text { Were you aware that all the generic drugs in national centralised } \\
\text { procurement have passed the consistency evaluation of quality and } \\
\text { efficacy? }\end{array}$ & 2067 (90.2) & $68(3.0)$ & $156(6.8)$ \\
\hline
\end{tabular}

drugs selected in the national centralised procurement programme have passed the consistency evaluation (2067; $90.2 \%)$. A high percentage of pharmacists $(1718 ; 75.0 \%)$ reported they were aware of how to identify generics that have passed consistency. However, only 225 (9.8\%) pharmacists correctly identified the pharmacokinetic parameters to be assessed in determining bioequivalence per consistency evaluation. Two thousand and seventy-eight $(90.7 \%)$ of pharmacists identified the correct definition of generic drugs have the same active ingredients, dosage forms, routes of administration and therapeutic effects as the brand drugs. Associations between knowledge items and characteristics are displayed in online supplemental table S3.

\section{Perceptions towards generic substitution}

Ten items were designed to assess attitudes on generic substitution. The Cronbach's alpha value for perception is equal to 0.833 . The total median score was calculated to be $37.00($ mean \pm SD: $37.07 \pm 4.503)$. Men had a higher total perception score and thus more positive attitude regarding generic substitution $(\mathrm{p}<0.001$; table 1$)$. Details on perceptions can be found in table 3 .

About two-thirds of the respondents agreed that generic drugs that passed the consistency evaluation were as effective $(1540 ; 67.3 \%)$ or as safe $(1581 ; 69.0 \%)$ as the brand-name equivalents. A total of $2063(90.1 \%)$ respondents reported that generic drugs have significant cost-minimising advantages over the brand-name drugs. One thousand three hundred and ninety-nine $(61.1 \%)$ pharmacists were of the opinion that generic drugs that passed the consistency evaluation were interchangeable with the brand-name drugs; while 784 (34.2\%) pharmacists held a neutral attitude towards interchangeability. Furthermore, $804(35.0 \%)$ respondents believed that replacing the brand-name drugs with generic drugs may change the clinical outcomes of medication treatment.

With regard to medication adherence, 1101 (48.1\%) respondents stated that the use of generic drugs could improve adherence to medication, but 1005 (43.9\%) respondents were neutral on this. A large percentage of respondents $(2009 ; 87.7 \%)$ recognised the importance of explaining detailed information about generic drugs to patients. While a similar percentage of respondents (1973; $86.2 \%$ ) highlighted the need for standard guidelines for generic substitution, $701(30.6 \%)$ thought that drugs that pass bioequivalence trials in vivo should be exempted from additional clinical trials before marketing. Seven hundred and fifty-nine $(33.1 \%)$ pharmacists were neutral about this, and $831(36.3 \%)$ disagreed. A large number of participant pharmacists $(1634 ; 71.4 \%)$ supported the national policy of generic substitution. A statistically significant association was found between geographic location and supportive attitudes toward generic substitution $(\mathrm{p}<0.001)$, see online supplemental table S4. The highest percentage of pharmacists in favour of generic substitution was from Xiamen $(78.9 \%)$, followed by Tianjin $(77.4 \%)$ and Beijing $(76.8 \%)$, while the lowest percentage was from Shanghai $(53.3 \%)$ (see online supplemental table S5).

A significant positive correlation was observed between pharmacists' perception on the efficacy and safety $(\rho=0.761 ; p<0.001)$. The positive attitude towards either efficacy $(\rho=0.681 ; p<0.001)$ or safety $(\rho=0.640 ; p<0.001)$ of generic drugs was associated with generic interchangeability. There were also significant associations between generic interchangeability and support for generic substitution $(\rho=0.602 ; p<0.001)$. In addition, a significant positive correlation was demonstrated between total knowledge score and total perception score $(\rho=0.267$; $\mathrm{p}<0.001)$. 
Table 3 Pharmacists' perceptions towards generic drugs

\begin{tabular}{|c|c|c|c|c|c|}
\hline Statement & $\begin{array}{l}\text { Strongly agree, } \\
\mathrm{N}(\%)\end{array}$ & $\begin{array}{l}\text { Agree, } \\
\mathrm{N}(\%)\end{array}$ & $\begin{array}{l}\text { Neutral, } \\
\text { N (\%) }\end{array}$ & $\begin{array}{l}\text { Disagree, } \\
\mathrm{N}(\%)\end{array}$ & $\begin{array}{l}\text { Strongly disagree, } \\
\text { N (\%) }\end{array}$ \\
\hline $\begin{array}{l}\text { Generic drugs that have passed the } \\
\text { consistency evaluation are as effective as } \\
\text { brand-name equivalents. }\end{array}$ & 361 (15.8) & 1179 (51.5) & $684(29.9)$ & $58(2.5)$ & $9(0.4)$ \\
\hline $\begin{array}{l}\text { Generic drugs that have passed the } \\
\text { consistency evaluation are as safe as } \\
\text { brand-name equivalents. }\end{array}$ & 355 (15.5) & 1226 (53.5) & 657 (28.7) & $50(2.2)$ & $3(0.1)$ \\
\hline $\begin{array}{l}\text { Generic drugs that have passed the } \\
\text { consistency evaluation are less expensive } \\
\text { than brand-name equivalents. }\end{array}$ & $1076(47.0)$ & 987 (43.1) & $218(9.5)$ & $10(0.4)$ & $0(0.0)$ \\
\hline $\begin{array}{l}\text { Generic drugs that have passed } \\
\text { the consistency evaluation are } \\
\text { interchangeable with brand-name drugs. }\end{array}$ & 314 (13.7) & 1085 (47.4) & 784 (34.2) & $96(4.2)$ & $12(0.5)$ \\
\hline $\begin{array}{l}\text { Replacing brand-name drugs with generic } \\
\text { drugs that passed the consistency } \\
\text { evaluation may change the clinical } \\
\text { outcomes of medication treatment. }\end{array}$ & 189 (8.2) & 615 (26.8) & $1047(45.7)$ & 387 (16.9) & $53(2.3)$ \\
\hline $\begin{array}{l}\text { Application of generic drugs that passed } \\
\text { the consistency evaluation could improve } \\
\text { adherence to medication treatment of } \\
\text { patients. }\end{array}$ & $228(10.0)$ & $873(38.1)$ & 1005 (43.9) & $169(7.4)$ & $16(0.7)$ \\
\hline $\begin{array}{l}\text { Health providers need to explain detailed } \\
\text { information about generic drugs to } \\
\text { patients in order to ensure that they } \\
\text { correctly understand and use generic } \\
\text { drugs. }\end{array}$ & 640 (27.9) & 1369 (59.8) & 258 (11.3) & $20(0.9)$ & $4(0.2)$ \\
\hline $\begin{array}{l}\text { Generic drugs can be exempted from } \\
\text { clinical trials for approval if they passed } \\
\text { bioequivalence trials in vivo. }\end{array}$ & 191 (8.3) & 510 (22.3) & 759 (33.1) & $673(29.4)$ & $158(6.9)$ \\
\hline $\begin{array}{l}\text { Relevant organisations should formulate } \\
\text { and issue standard guidelines for generic } \\
\text { substitution. }\end{array}$ & 661 (28.9) & $1312(57.3)$ & 296 (12.9) & $20(0.9)$ & $2(0.1)$ \\
\hline $\begin{array}{l}\text { I support the current policy of substituting } \\
\text { brand-name drugs with generic drugs that } \\
\text { have passed the consistency evaluation. }\end{array}$ & 409 (17.9) & 1225 (53.5) & 619 (27.0) & $32(1.4)$ & $6(0.3)$ \\
\hline
\end{tabular}

\section{Practices on generic substitution}

A total of $1850(80.8 \%)$ pharmacists noted increased use of generic drugs in their medical institutions, of whom $1046(45.7 \%)$ reported a dramatically increased trend. Table 4 illustrates possible influencing factors related to dispensing and selection of generic drugs; most pharmacist respondents reported that the three main factors affecting their willingness to dispense generic drugs were efficacy $(25.0 \%)$, safety $(19.2 \%)$ and the direction of national policies and hospital regulations $(18.7 \%)$.

Pharmacists reported that they think the top three factors patients considered when selecting generic drugs were efficacy of generic drugs $(23.9 \%)$, preferences for brand-name drugs and medication habits $(19.9 \%)$, and safety of generic drugs (17.4\%). The most commonly cited difficulties in implementation of the centralised procurement and use of generic drugs were lack of trust in efficacy and safety (31.0\%), challenge to change patients' preference $(29.0 \%)$ and lack of time to provide patient education (23.6\%). Suggestions for promoting generic substitution included encouraging generic substitution by health insurance policies $(27.6 \%)$, publicising these policies $(25.5 \%)$ and educating health providers about generics and guidelines regarding their use (21.1\%).

\section{DISCUSSION}

This cross-sectional study is one of the few surveys evaluating the knowledge, perceptions and practices of pharmacists regarding generic drugs after implementing the national centralised procurement in China. The Cronbach's alpha value for perceptions is equal to 0.833 , indicating a good level of reliability. The total knowledge score $(\mathrm{p}<0.05)$ and the total perception score $(\mathrm{p}<0.05)$ were proven non-normally distributed using KolmogorovSmirnov test. Mann-Whitney U or Kruskal-Wallis tests were used to compare differences. 
Table 4 Generic substitution practices

Item
How has the amount of generic drugs
after the implementation of national
centralised procurement of drugs?
What factors do you think affect the
selection of generic drugs? Please select
the top three important items.

the top three important items.

\begin{tabular}{|c|c|}
\hline Statement & $\mathbf{N}(\%)$ \\
\hline Significantly increased & $1046(45.7)$ \\
\hline Increased somewhat & $805(35.1)$ \\
\hline Basically unchanged & $163(7.1)$ \\
\hline Decreased & $23(1.0)$ \\
\hline Unsure & $254(11.1)$ \\
\hline National policies and hospital regulations & $1284(18.7)$ \\
\hline Efficacy of generic drugs & $1716(25.0)$ \\
\hline Safety of generic drugs & $1321(19.2)$ \\
\hline Economy of generic drugs & $686(10.0)$ \\
\hline Accessibility to generic drugs and brand-name drugs & $350(5.1)$ \\
\hline Physicians' clinical expertise in medication treatment & $324(4.7)$ \\
\hline Patients' financial burden & $357(5.2)$ \\
\hline Patients' willingness and preferences & $548(8.0)$ \\
\hline Promotion of drug representatives & $94(1.4)$ \\
\hline Reputation of generic drugs manufacturers & $182(2.6)$ \\
\hline Others & $11(0.2)$ \\
\hline Patients' preference for brand-name drugs and medication habits & $1368(19.9)$ \\
\hline Efficacy of generic drugs & $1641(23.9)$ \\
\hline Safety of generic drugs & $1198(17.4)$ \\
\hline Out-of-pockets cost of drugs & $737(10.7)$ \\
\hline Patients' financial burden & $888(12.9)$ \\
\hline Physicians' suggestions & $625(9.1)$ \\
\hline National policies & $412(6.0)$ \\
\hline Others & $4(0.1)$ \\
\hline There is no enough time to explain details to patients & $1621(23.6)$ \\
\hline It is difficult to change patients' preference & $1992(29.0)$ \\
\hline Lack of trust in the efficacy and safety of generic drugs & $2134(31.0)$ \\
\hline There is an increased risk of errors in dispensing drugs & $529(7.7)$ \\
\hline There is an increased cost in maintenance and manpower & $558(8.1)$ \\
\hline Others & $39(0.6)$ \\
\hline
\end{tabular}

What measures should be taken to promote the national centralised procurement and use of generic drugs? Please select the top three important items.

What factors do you think affect patients' choice of selecting generic drugs in the national centralised procurement? Please select the top three important items.

What do you think is the largest challenge in implementing the national centralised procurement and use of generic drugs? Please select the top three important items.

Encourage patients to use generic drugs by use of health insurance policies

Increase publicity of centralised procurement policies

$1751(25.5)$

Educate health providers on centralised procurement policies and $1450(21.1)$ information about selected drugs

Medical institutions should restrict the use of the brand-name drugs $513(7.5)$ with the same generic name, and retain only the selected generic drugs

Medical institutions should restrict the use of all brand-name drugs with the same pharmacological action

Standard guidelines on generic substitution should be issued

$942(13.7)$

Others

$47(0.7)$

This survey recruited a large number of respondents. In general, pharmacists had fair amount of knowledge regarding consistency evaluation and the definition of generic drugs. It appears that Chinese pharmacists are generally supportive of generic substitution; although, they still acknowledge some reservations regarding the quality, efficacy and safety of generic drugs. Measures such as encouraging generic substitution by health 
insurance programmes, publicising generic drugs policies, educating health providers about generics and guidelines regarding their use should be taken to promote generic substitution.

In this study, more than $90 \%$ of the respondents were aware of the definition of generic drugs. This was higher than some published studies, in other countries, like Poland, ${ }^{29}$ Pakistan, ${ }^{30}$ Malaysia ${ }^{31}$ and New Zealand. ${ }^{32}$ In our study, few respondents (9.8\%) identified the correct criteria for bioequivalence. This lack of knowledge on the robustness of regulatory requirements may lead to less confidence in the quality of generic drugs. In studies set in Palestine and the USA, community pharmacists were asked to identify the correct Food and Drug Administration acceptance criteria for bioequivalence; a similar percentage of community pharmacists $(12.6 \%$ vs $7.3 \%)$ provided the correct answer. ${ }^{23} 33$ Nearly $30 \%$ of respondents had a neutral attitude towards efficacy (29.9\%), safety $(28.7 \%)$ of generic drugs and interchangeability with brand-name equivalents $(34.2 \%)$. The reason may be that the quality of generic drugs may not be clearly evident in pharmacists' clinical practice sites since generic substitution had only been implemented for 1 year. Seventy-one per cent of Chinese pharmacists surveyed supported the national policy of generic substitution. These results were similar to various studies conducted in Iran $(71.6 \%),{ }^{34}$ Poland $(67.1 \%),{ }^{29}$ Saudi Arabia $(68.5 \%),{ }^{22}$ Lebanon $(64 \%),{ }^{35}$ while lower than that in Australia (93.7\%), ${ }^{36}$ Nigeria $(92.9 \%),{ }^{37}$ French $(90 \%),{ }^{38}$ Ireland $(80 \%){ }^{39}$

It was interesting to find a significant positive correlation between total knowledge score regarding generics and total perception score, indicating that pharmacists who are more knowledgeable in generic drugs may hold a more supportive attitude towards generic substitution. This may suggest the importance of mass educational effort among pharmacists. More information on the issues of generic drugs makes pharmacists confident in using and dispensing those products. Besides, significant differences were observed by location in both knowledge and perception, which could lead to locational differences in the implementation of the generic substitution policy.

In more recent years, China has made a significant effort to promote generic substitution. The NMPA requires that generic drugs approved before 2007 must be proved bioequivalent with brand innovators by the end of 2021. Drug products that have not passed the consistency evaluation will no longer be selected for the national centralised drug procurement if more than three other generic drug manufacturers have passed. On average drug prices dramatically decreased by $52 \%$ of the selected drugs because of price negotiations and volume-based national centralised drug procurement. ${ }^{40}$ In 2017, NMPA published Approved Drug Lists in China, similar to the US's Orange Book, this list includes 17 varieties of approved generic drugs passed the consistency evaluation. Pharmaceutically equivalent products and therapeutically equivalent products are clearly coded in this list. However, further steps need to be taken to educate pharmacists.

To correct misconceptions on generic drugs, the NMPA should ensure that generic drugs meet quality standards by using the Good Manufacturing Practices. The generic drug approval process should be rigorous and transparent to the public. Negative perceptions and skepticisms can be reduced through education that will create more awareness about generic drugs and the importance of generic substitution among healthcare providers and patients. As some studies have demonstrated, information with regard to generic substitution should be taught in college curricula to better prepare healthcare providers for future work. $223141-47$

One proposed measure that could be implemented to promote rational use of generic drugs is the establishment of standard operating procedures for generic substitution and formulary of the medical institutions. ${ }^{31}$ Currently, generic drugs use has been greatly encouraged in public hospitals in the 11 pilot locations. Although this national centralised procurement brought tremendous use of generic drugs, physicians tend to veer towards using brand-name drugs with the same pharmacological action when one brand-name drug was not accessible. A small number of our survey respondents agreed that in order to promote generic substitution medical institutions should restrict the use of brand-name drugs $513(22.4 \%)$ and 271 $(11.8 \%)$ responded that hospitals should only retain the corresponding generic drugs or drugs in the same pharmacological drug class.

In this survey, only a few pharmacists reported other factors influencing patients' acceptance of generic substitution, such as patients' financial burden (12.9\%), out-of-pockets cost of drugs $(10.7 \%)$ and physicians' suggestions $(9.1 \%)$. Currently, generic substitution has been supported by several Chinese health insurers, providing greater reimbursement for generic drugs (vs brand-name drugs). Many countries enacted generic drugs prices and reimbursement policy to promote generic substitution. ${ }^{34} 48-51$ The survey respondents were from well-developed cities in China, so the difference in drug cost may not have been a barrier for these patients. However, the cost-saving factor may be pivotal for patients in lower-income areas. A nationwide study conducted in Australian pharmacies demonstrated that the pharmacists' generic substitution recommendation rate in urban and rural areas was significantly higher than remote areas, while the patients' acceptance rate in remote areas was significantly higher than that in rural and urban areas. ${ }^{52}$ Therefore, cost may not be the only incentive that should be offered to encourage generic substitution in high-income areas. In our study, some of the respondents proposed that supply issues for generic drugs resulted in frequent medication changes and poor medication adherence. Therefore, supply guarantee of selected drugs and sustainability of formulary in the national procurement should be strengthened. The government should 
formulate regulations or acts for consistent evaluation of generic drugs and rigid quality supervision.

Pharmacists play a key role in managing rational use of medications, balancing between efficacy, safety and economic use of drugs. Pharmacotherapy monitoring and adverse drug reaction reporting should be emphasised to identify safety concerns regarding generic drugs. It is important for pharmacists to provide proper education to prevent patient confusion related to generic substitution and thus improve patient adherence. Pharmacists should also provide education and guidance to physicians and consumers on proper use of generic drugs. Only by understanding and appreciating the quality of generic drugs can patients and physicians have full confidence in generic substitution. Therefore, attitudes of pharmacists may be a crucial factor affecting the acceptance of generics by both physicians and patients. Three systematic reviews identified that a significant proportion of physicians, pharmacists and patients hold negative perceptions of generic drugs, perceiving generics as less effective, less safe and inferior in quality. ${ }^{25-27}$ Physicians and patients expressed more negative opinions than pharmacists. All these publications indicated that negative attitudes present barriers to the generic substitution, and education of stakeholders was a requirement for increased usage of generics.

In some states in the USA, pharmacists must substitute a generically equivalent drug if available. Other states allow the pharmacists to decide to provide substitution-if not otherwise indicated by the physician. And still, other states impose an additional restriction that require pharmacists to obtain patients' consent before substituting with a generic product. ${ }^{53-55} \mathrm{~A}$ study investigated the effects of state-level pharmacist regulations on generic substitution of prescription drugs and concluded that mandates generic substitution by pharmacists was found to have an insignificant effect. ${ }^{55}$ A review on pharmaceutical regulation in 15 European countries demonstrated that pharmacists are entitled to substitution in Denmark, Germany, Ireland, Poland and UK. Generic substitution is even mandatory for pharmacists in Belgium, Finland, Greece, Italy, Netherlands, Portugal, Spain and Sweden, and incentivised in France. ${ }^{51}$ Several studies from Lebanon, Palestine and Qatar concluded pharmacists should have authority to perform generic substitution without consulting the prescribing physicians. ${ }^{23} 3556$ However, pharmacists do not have authority to modify medication orders to allow for substitution in China, they usually dispense drugs according to medical prescription, thus further progress needs to be made to improve this situation. We believe pharmacists may be authorised in implementing generic substitution for any medication in future.

There are some limitations for this research. This study was performed in 11 locations in China, and most respondents were from large public hospitals; therefore, findings cannot be generalised to pharmacists practicing in other cities in China. The survey had limited access to pharmacists in community settings or rural areas. This also limits generalisability of the findings. The data were not collected from a random sample, which may weaken the representativeness and the results on the statistical significance of the differences and correlations presented about the data. Moreover, because of the web-based sample survey tool, we cannot compute a response rate to the questionnaire and adjust for possible non-response bias. In addition, due to the self-administered format of questionnaires, we cannot rule out the possibility of social desirability bias because the content of questionnaires about generic substitution correlates to the national policies and politics as well as the knowledge scores represent the respondents' perception.

This survey can serve as a preliminary study and is helpful in understanding the knowledge and perceptions of pharmacists on issues pertaining to generic drugs, and exploring the factors hindering and favouring generic substitution in China. The current findings have important implications in continuous improvement of generic drugs policy and its implementation. Future research is needed to explore physicians' and patients' perceptions and practices regarding the establishment of national centralised procurement and generic substitution programme in China. Generic drugs on the market are required to be bioequivalent to the reference product; however, their therapeutic equivalence may not necessarily be identical, especially for narrow therapeutic index drugs. ${ }^{47}$ 57-60 Therefore, evidence of the efficacy and safety of generic drugs should be obtained from real-world studies to prove therapeutic equivalence.

\section{CONCLUSION}

The study concluded that Chinese pharmacists have a fairly good knowledge of generic drugs used in the national centralised procurement programme and generally have positive attitudes towards generic substitution. The main obstacle for further utilisation of generic drugs is lack of trust in efficacy and safety. Education and awareness of generic substitution should be promoted and clear standard guidelines need to be created. All these issues need to be addressed for the realisation of the true value of generic drugs as part of the country's healthcare cost-containment strategy as well as the implementation of generic substitution policy in China.

\footnotetext{
Author affiliations

${ }^{1}$ Department of Pharmacy, State Key Laboratory of Complex Severe and Rare Diseases, Peking Union Medical College Hospital, Chinese Academy of Medical Sciences and Peking Union Medical College Hospital, Beijing, China

${ }^{2}$ Department of Medical Administration, Peking Union Medical College Hospital, Chinese Academy of Medical Sciences and Peking Union Medical College Hospital, Beijing, China

${ }^{3}$ Department of Pharmacy Practice, St. Louis College of Pharmacy, St Louis, Missouri, USA

${ }^{4}$ Department of Pharmaceutical and Administrative Sciences, St. Louis College of Pharmacy, St Louis, Missouri, USA
} 
Acknowledgements The authors would like to thank all the pharmacists who participated in the study. The authors would also like to express their gratitude to all the experts and researchers for providing feedback on this questionnaire.

Contributors JQ led the overall study design, conducted the statistical analyses, interpreted the data, and wrote the first draft of the manuscript. WZ and BZ made the study design, collected the data, contributed to interpretation of findings and edited the manuscript. SW, LD, XL, YG, JL, XD and DM were involved in the design of the questionnaire. HP, LD, XD and DM participated in distributing the questionnaire. RT, KS and SL contributed to editing the manuscript and interpretation of findings. All the authors read, made comments on manuscripts, approved the final manuscript and agreed on its submission. BZ is responsible for the overall content as guarantor.

Funding This study was partially funded by Peking Pharmacological Society. Competing interests None declared.

Patient consent for publication Not applicable.

Ethics approval The study was approved by the Institutional Review Board (IRB) of Peking Union Medical College Hospital in China (IRB\#: S-K1136) and St. Louis College of Pharmacy in the USA (IRB\#: 2020-18). Anonymity was ensured by gathering and analysing data in aggregate and only allowing members of the research team access to the password-protected data.

Provenance and peer review Not commissioned; externally peer reviewed.

Data availability statement Data are available upon reasonable request. Data are available on reasonable request. The data generated and/or analyzed during the present study are not publicly available, but they are available from the corresponding author on reasonable request.

Supplemental material This content has been supplied by the author(s). It has not been vetted by BMJ Publishing Group Limited (BMJ) and may not have been peer-reviewed. Any opinions or recommendations discussed are solely those of the author(s) and are not endorsed by BMJ. BMJ disclaims all liability and responsibility arising from any reliance placed on the content. Where the content includes any translated material, BMJ does not warrant the accuracy and reliability of the translations (including but not limited to local regulations, clinical guidelines, terminology, drug names and drug dosages), and is not responsible for any error and/or omissions arising from translation and adaptation or otherwise.

Open access This is an open access article distributed in accordance with the Creative Commons Attribution Non Commercial (CC BY-NC 4.0) license, which permits others to distribute, remix, adapt, build upon this work non-commercially, and license their derivative works on different terms, provided the original work is properly cited, appropriate credit is given, any changes made indicated, and the use is non-commercial. See: http://creativecommons.org/licenses/by-nc/4.0/.

\section{ORCID iDs}

Hui Pan http://orcid.org/0000-0003-2413-0646

Bo Zhang http://orcid.org/0000-0003-2643-0706

\section{REFERENCES}

1 Squires D, Anderson C. U.S. health care from a global perspective: spending, use of services, prices, and health in 13 countries. Issue Brief 2015;15:1-15.

2 Hassali MA, Alrasheedy AA, McLachlan A, et al. The experiences of implementing generic medicine policy in eight countries: a review and recommendations for a successful promotion of generic medicine use. Saudi Pharm J 2014;22:491-503.

3 Wouters OJ, Kanavos PG, McKEE M. Comparing generic drug markets in Europe and the United States: prices, volumes, and spending. Milbank Q 2017;95:554-601.

4 Wouters OJ, Kanavos PG. A comparison of generic drug prices in seven European countries: a methodological analysis. BMC Health Serv Res 2017;17:242.

5 Vogler S, Paris V, Ferrario A, et al. How can pricing and reimbursement policies improve affordable access to medicines? lessons learned from European countries. Appl Health Econ Health Policy 2017;15:307-21.

6 World Health Organization. Multisource (generic) pharmaceutical products: guidelines on registration requirements to establish interchangeability, 2005. Available: http://www.who.int/medicines/ services/expertcommittees/pharmprep/QAS04_093Rev4_final.pdf

7 Posner J, Griffin JP. Generic substitution. Br J Clin Pharmacol 2011;72:731-2
8 National Health Commission. Chinese health statistics Yearbook 2019. Beijing, China: National Bureau of Statistics, 2020.

9 Yip W, Fu H, Chen AT, et al. 10 years of health-care reform in China: progress and gaps in universal health coverage. Lancet 2019;394:1192-204.

10 Manning N. The Reform of Health Policy in China - Left Behind in the Race to Industrialize? Soc Policy Adm 2011;45:649-61.

11 Cameron A, Mantel-Teeuwisse AK, Leufkens HGM, et al. Switching from originator brand medicines to generic equivalents in selected developing countries: how much could be saved? Value Health 2012;15:664-73.

$12 \mathrm{Hu} \mathrm{L,} \mathrm{Yu} \mathrm{Z,} \mathrm{Yuan} \mathrm{Q,} \mathrm{et} \mathrm{al.} \mathrm{Opportunities} \mathrm{and} \mathrm{challenges} \mathrm{of}$ multinational pharmaceutical Enterprises in transforming pharmaceutical market in China. Ther Innov Regul Sci 2019;53:207-14.

13 Huang B, Barber SL, Xu M, et al. Make up a missed lesson-New policy to ensure the interchangeability of generic drugs in China. Pharmacol Res Perspect 2017;5:e00318.

14 Lulin Z, Antwi HA, Wang W, et al. The effect of herd formation among healthcare investors on health sector growth in China. Int $J$ Equity Health 2016;15:113.

15 Zuo J, Gao Y, Bou-Chacra N, et al. Challenges and opportunities to use biowaivers to compare generics in China. AAPS PharmSciTech 2014;15:1070-5.

16 China Food and Drug Administration. Evaluation scheme of generic quality consistency. China food and drug administration, 2013. Available: http://www.nmpa.gov.cn/WS04/CL2196/323980.html [Accessed 31 May 2020].

17 State Council of the People's Republic of China. Notification on the carrying out consistency evaluation of the quality and efficacy of generic drugs. Available: http://www.gov.cn/zhengce/content/201603/05/content_5049364.htm [Accessed 31 May 2020].

18 National Medical Products Administration. Guidelines on statistical analysis in bioequivalence studies and technology in bioequivalence studies of high-variation drugs. Available: http://www.nmpa.gov.cn/ WS04/CL2138/331454.html [Accessed 31 May 2020].

19 State Council Information Office. Regular meeting on the state Council policy on 27th, November,2019. Available: http://www.nhc. gov.cn/xcs/s7847/201911/dad7e0b2a26a4 f56bd68836d33ab2fe2. shtml [Accessed 08 August 2020].

20 Analysis and prediction of China's generic drug industry development status and scale in 2020. Available: https://www.chyxx.com/industry/ 202005/860003.html [Accessed 26 Aug 2021].

21 WANG Y, XU W, LU N. Analysis of the effect of " $4+7$ " centralized procurement policy implementation: Based on the drug sales data of 9 pilot regions. Chinese Journal of Health Policy 2021;14.

22 Alkhuzaee FS, Almalki HM, Attar AY, et al. Evaluating community pharmacists' perspectives and practices concerning generic medicines substitution in Saudi Arabia: a cross-sectional study. Health Policy 2016;120:1412-9.

23 Shraim NY, Al Taha TA, Qawasmeh RF, et al. Knowledge, attitudes and practices of community pharmacists on generic medicines in Palestine: a cross-sectional study. BMC Health Serv Res 2017; $17: 847$.

24 Tsaprantzi AV, Kostagiolas P, Platis C, et al. The impact of information on doctors' attitudes toward generic drugs. Inquiry 2016;53:0046958016637791.

25 Colgan S, Faasse K, Martin LR, et al. Perceptions of generic medication in the general population, doctors and pharmacists: a systematic review. BMJ Open 2015;5:e008915.

26 Toverud E-L, Hartmann K, Håkonsen H. A systematic review of physicians' and pharmacists' perspectives on generic drug use: what are the global challenges? Appl Health Econ Health Policy 2015;13 Suppl 1:35-45.

27 Dunne SS, Dunne CP. What do people really think of generic medicines? A systematic review and critical appraisal of literature on stakeholder perceptions of generic drugs. BMC Med 2015;13:173.

28 Dunne SS. What do users of generic medicines think of them? A systematic review of consumers' and patients' perceptions of, and experiences with, generic medicines. Patient 2016;9:499-510.

29 Drozdowska A, Hermanowski T. Exploring factors underlying the attitude of community pharmacists to generic substitution: a nationwide study from Poland. Int J Clin Pharm 2016;38:162-70.

30 Jamshed S, Hassali M, Ibrahim M, et al. Knowledge, perception and attitude of community pharmacists towards generic medicines in Karachi, Pakistan: a qualitative insight. Trop J Pharm Res 2010;9:58943.

31 Chua GN, Hassali MA, Shafie AA, et al. A survey exploring knowledge and perceptions of general practitioners towards the use of generic medicines in the Northern state of Malaysia. Health Policy 2010;95:229-35. 
32 Babar Z-U-D, Grover P, Stewart J, et al. Evaluating pharmacists' views, knowledge, and perception regarding generic medicines in New Zealand. Res Social Adm Pharm 2011;7:294-305.

33 Euen BJ, Fadda HM. Community pharmacists' understanding and perceptions of FDA therapeutic equivalence standards. Res Social Adm Pharm 2019;15:77-83.

34 Nazila Y, Gholamhossein M, Farzad P. Generic substitution policy implementation: a pharmacists' perspective survey. Journal of generic medicines 2015.

35 El-Jardali F, Fadlallah R, Morsi RZ, et al. Pharmacists' views and reported practices in relation to a new generic drug substitution policy in Lebanon: a mixed methods study. Implement Sci 2017;12:23.

36 Ping CC, March G, Clark A, et al. A Web-Based Survey on Australian Community Pharmacists' Perceptions and Practices of Generic Substitution. Journal of Generic Medicines 2010;7:342-53.

37 Auta A, Bala ET, Shalkur D. Generic medicine substitution: a crosssectional survey of the perception of pharmacists in north-central, Nigeria. Med Princ Pract 2014;23:53-8.

38 Allenet B, Barry H. Opinion and behaviour of pharmacists towards the substitution of branded drugs by generic drugs: survey of 1,000 French community pharmacists. Pharm World Sci 2003;25:197-202.

39 Dunne SS, Shannon B, Cullen W, et al. Perceptions and attitudes of community pharmacists towards generic medicines. J Manag Care Spec Pharm 2014;20:1138-46.

40 China Daily. China to further pilot medicine procurement program. Available: https://www.chinadaily.com.cn/a/201904/04/WS5ca5fe 88a3104842260b4844.html [Accessed 08 Aug 2020].

41 Shrank WH, Liberman JN, Fischer MA, et al. Physician perceptions about generic drugs. Ann Pharmacother 2011;45:31-8.

42 Al-Tamimi SK, Hassali MA, Shafie AA, et al. The need to incorporate generic medicines topic in the curriculum of Yemeni pharmacy colleges. Int J Pharm Pract 2016;24:72-3.

43 Alrasheedy AA, Hassali MA, Aljadhey $\mathrm{H}$, et al. The need to cover generic medications and generic substitution practice in the curricula of pharmacy colleges in Saudi Arabia. Am J Pharm Educ 2014;78:108.

44 Domeyer PJ, Aletras V, Anagnostopoulos F, et al. Development and validation of a tool to assess knowledge and attitudes towards generic medicines among students in Greece: the attitude towards generics (ATTOGEN) questionnaire. PLOS One 2017;12:e0188484.

45 Domeyer PJ, Katsari V, Sarafis P, et al. Greek students' attitudes, perception and knowledge regarding generic medicines in times of economic crisis: a cross-sectional study. BMC Med Educ 2018;18:262.
46 James PB, Bah AJ, Margao EK, et al. Exploring the knowledge and perception of generic medicines among final year undergraduate medical, pharmacy, and nursing students in Sierra Leone: a comparative cross-sectional approach. Pharmacy 2018:6:3.

47 Chong CP, Hassali MA, Bahari MB, et al. Exploring community pharmacists' views on generic medicines: a nationwide study from Malaysia. Int J Clin Pharm 2011;33:124-31.

48 Mansfield SJ. Generic drug prices and policy in Australia: room for improvement? A comparative analysis with England. Aust Health Rev 2014;38:6-15.

49 Ferrario A, Dedet G, Humbert T, et al. Strategies to achieve fairer prices for generic and biosimilar medicines. BMJ 2020;368:15444.

50 Rodwin MA. How the United Kingdom controls pharmaceutical prices and spending: learning from its experience. Int $J$ Health Serv 2021:51:229-37.

51 Panteli D, Arickx F, Cleemput I. Pharmaceutical regulation in 15 European countries review. Health Syst Transit 2016;18:1-122.

52 Chong CP, March G, Clark A, et al. A nationwide study on generic medicines substitution practices of Australian community pharmacists and patient acceptance. Health Policy 2011;99:139-48.

53 Assistant Secretary for Planning and Evaluation (ASPE) U.S. Department of Health and Human Services. Expanding the use of generic drugs. Available: https://aspe.hhs.gov/basic-report/ expanding-use-generic-drugs\#Legislative [Accessed 21 Jun 2020].

54 Darrow JJ, Chong JE, Kesselheim AS. Reconsidering the scope of US state laws allowing pharmacist substitution of generic drugs. BMJ 2020;369:m2236.

55 Song Y, Barthold D. The effects of state-level pharmacist regulations on generic substitution of prescription drugs. Health Econ 2018;27:1717-37.

56 Awaisu A, Kheir N, Ibrahim MIM, et al. Knowledge, attitudes, and practices of community pharmacists on generic medicines in Qatar. Int J Clin Pharm 2014;36:394-404.

57 Sarpatwari A, Lee MP, Gagne JJ, et al. Generic versions of narrow therapeutic index drugs: a national survey of pharmacists substitution beliefs and practices. Clin Pharmacol Ther 2018;103:1093-9.

58 Atif M, Azeem M, Sarwar MR. Potential problems and recommendations regarding substitution of generic antiepileptic drugs: a systematic review of literature. Springerplus 2016;5:182.

59 Dunne S, Shannon B, Hannigan A, et al. Physician and pharmacist perceptions of generic medicines: what they think and how they differ. Health Policy 2014;116:214-23.

60 Yamada M, Welty TE. Generic substitution of antiepileptic drugs: a systematic review of prospective and retrospective studies. Ann Pharmacother 2011;45:1406-15. 